\title{
Effects of the nickel, copper, silver and tin coating on S235JR, 21NiCrMo2, C45 and 42CrMo4 steels for radiation shielding performance
}

\author{
İdris Karagöz ${ }^{1(D)}$, Erdem Şakar² (D), Murat Türemiş ${ }^{3 *(D)}$, Mehmet Büyükyıldız ${ }^{3}$ (iD \\ ${ }^{1}$ Faculty of Engineering, Department of Polymer Materials Engineering, Yalova University, Yalova, Turkey \\ ${ }^{2}$ Faculty of Science, Department of Physics, Ataturk University, 25240 Erzurum, Turkey \\ ${ }^{3}$ Faculty of Engineering and Natural Sciences, Department of Physics, Bursa Technical University, Bursa, Turkey \\ * muratturemis@ @otmail.com \\ *Orcid: 0000-0001-8849-4364
}

Received: 4 February 2021

Accepted: 11 August 2021

DOI: $10.18466 /$ cbayarfbe. 874287

\begin{abstract}
In this study, S235JR (1.0037), 21NiCrMo2 (1.6523), C45 (1.0503), 42CrMo4 (1.7225) steels were coated with nickel, copper, silver, and tin. Then, the radiation shielding performances of the uncoated and coated steels were investigated. The steels were firstly designed by the coating processes via electrolytic plating method on behalf of $\mathrm{Ni}, \mathrm{Cu}, \mathrm{Ag}$ and $\mathrm{Sn}$ metals. The samples were then irradiated by radioactive sources for transmission of the gamma rays at photon energies in the range $81-383 \mathrm{keV}$ photon energies to measure linear and mass attenuation coefficients (LAC $-\mu, \mathrm{MAC}-\mu / \rho)$ of the pure and coated steels by $\mathrm{Ni}, \mathrm{Cu}, \mathrm{Ag}$ and $\mathrm{Sn}$. Half and tenth value of layers (HVL and TVL) of investigated materials were then calculated at the same studied photon energies. The materials were compared with each other as well as with some shielding concretes in terms of mean free paths (MFP) wherever possible. The coated steels were found to be better shielding materials than the concretes due to lower MFP values they had, and they showed also better shielding than reference materials up to $35.31 \%$ relative difference in MFP. It was concluded that coating processes improved the shielding properties of the steels.
\end{abstract}

Keywords: Coating, radiation shielding, steel

\section{Introduction}

The steels are generally known as iron-carbon alloys, have different types based on iron alloys on behalf of mechanical, physical, and chemical properties required to use. They are widely utilized in various areas such as engineering, security systems in military, public and private buildings, nuclear power plants, shipbuilding, structural materials etc. due to their well physical and mechanical quantities. On the other hand, with the increasing use of the $\mathrm{X}$ - and/or gamma rays in different fields such as nuclear plants, medical facilities and laboratories, it is frequently required the new types of materials against the hazardous radiations. For this aim, we can use the concretes, glasses, heavy metals, different steels etc. The resistance of steels to radiation damage gains importance especially when their strength, chemical composition, resistance to corrosion, weldability and ductility properties are taken into account $[1,2]$.
Some steels have been generally investigated in some $\mathrm{X}$ - and/or gamma ray energies for shielding applications in the literature. And the studies have experimental and/or theoretical values and can show radiation shielding properties of the materials. They can also explain linear attenuation coefficient $\left(\mathrm{cm}^{-1}, \mu\right.$, LAC), mass attenuation coefficient $\left(\mathrm{cm}^{2} \cdot \mathrm{gr}^{-1}, \mu_{m}\right.$, MAC), mean free path (cm, MFP), half values of layer (cm, HVL), tenth values of layer (cm, TVL), effective atomic number $\left(\mathrm{Z}_{\mathrm{eff}}\right)$, effective electron density $\left(\mathrm{N}_{\mathrm{eff}}\right)$ and buildup factors for steels [3-14]. Alım et al. [15] have recently determined radiation parameters of AISI-coded stainless steels (Part 1) both experimentally and theoretically at different photon energies. And AISI 300 austenitic stainless-steel series containing $\mathrm{Ni}$ have been found superior when compared to the other materials in the study. Gamma charged particle and fast neutron interactions of AISI-302, 304, 321 and 430 stainless steels have been calculated and evaluated in terms of shielding performance [16]. And authors said that 
studied steels had excellent shielding properties than shielding concretes.

It is considered that materials such as 1.0037 (S235JR), 1.6523 (21NiCrMo2), 1.0503 (C45), 1.7225 (42CrMo4) steels, which are frequently used in machine industry and structural elements in the industry, can be used in the production of reactor components or control equipment when their chemical contents are taken into account. But the surface quality, corrosion resistance, machinability and weldability of steel materials are important in applications or usage because they can affect the physical properties of the materials [17,18]. However, the fact that the corrosion resistance of these materials is not as well as stainless steels constitutes a disadvantage [19]. The corrosion resistance of steels can be increased by the coating method applied for purposes such as adding aesthetic properties to materials, increasing the lifetime of materials by increasing their surface hardness and providing abrasion resistance, and conductivity. Metal coating methods or designs that are commonly used for this purpose in the industry are zinc coating, TiN coating, silver coating, nickel coating, and copper coating methods [20]. These operations can change or improve some properties of the materials. So, some physical properties of the materials can be changed after coating, and it should be important to determine these possible changes in the materials for applications. But radiation shielding capability or effectiveness of materials after coating processes have not been taken into consideration in literature as far as is determined. Whereas radiation shielding capabilities of the materials may be changed, even improved after coating processes via useful designs. This is the motivation of the present study. In the present study, 1.0037 (S235JR), 1.6523 (21NiCrMo2), 1.0503 (C45), 1.7225 (42CrMo4) steels were coated with $\mathrm{Ni}, \mathrm{Cu}, \mathrm{Ag}$ and $\mathrm{Sn}$ to investigate possible developments of the coatings on radiation shielding properties.

\section{Materials and Methods}

\subsection{Sample preparation}

The prepared samples were plated by the electrolytic plating method and chemical compositions and formulas of the samples were given at Table 1. In general, the sequential steps presented in Figure 1 were followed in all coating processes. In the copper plating process, the samples, which were first subjected to the predegreasing process, were etched with acid using 30\% HCL and $1 \%$ inhibitor after washing. The samples that were washed after etching were subjected to $5 \%$ degreasing salt, cathodic 4-8 $\mathrm{A} / \mathrm{dm}^{2}$ and electrolytic degreasing for 3 minutes. The copper plating process was performed for 10 minutes using $60{ }^{\circ} \mathrm{C}, 2-3$ Volt, $0.5-1 \mathrm{~A} / \mathrm{dm}^{2}$ plating parameters. The samples, which were washed again for 10 seconds after the neutralization process in $10 \% \mathrm{H}_{2} \mathrm{SO}_{4}$ solution, were dried with hot air.

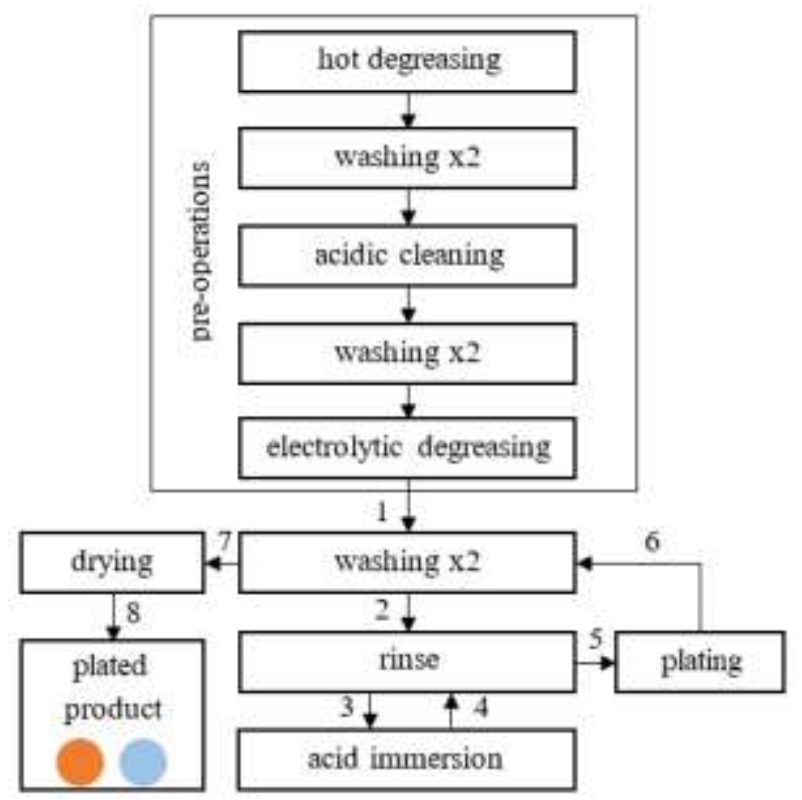

Figure 1. Followed in all coating processes.

The samples subjected to the polishing process in the silver-plating process were cleaned using hot mechanical lubricants. The cleaned samples were subjected to the oxide removal process in the solution containing $100 \mathrm{gr} / \mathrm{l} \mathrm{NaCN}$. After the oxide removal process, 5\% degreasing salt, cathodic 4-8 A/dm ${ }^{2}$ and electrolytic degreasing for 3 minutes were applied. The washed samples were subjected to the neutralization process for 20 seconds in the solution containing 100 $\mathrm{gr} / \mathrm{l}$ potassium. The neutralized samples were pre-plated with silver for 2 minutes using $120 \mathrm{gr} / 1$ silver powder, $0.02-0.01 \mathrm{~A} / \mathrm{dm}^{2}$. The pre-silver-plated samples were silver plated using $180 \mathrm{gr} / 1$ silver powder, $4 \mathrm{gr} / 1$ silver cleaner, and $4 \mathrm{gr} / \mathrm{l}$ silver moisturizer. After silver plating, the samples were washed in hot water at $70{ }^{\circ} \mathrm{C}$ for 3 minutes.

In the nickel-plating process, the samples were first subjected to the pre-degreasing process, and after washing, they were etched with acid using $10 \% \mathrm{H}_{2} \mathrm{SO}_{4}$ solution. The electrolytic degreasing process was applied to the samples that were washed after etching. The nickel-plating process was performed for 10 minutes using $25 \mathrm{gr} / 1$ nickel chloride, $60{ }^{\circ} \mathrm{C}$, 2-3 Volt, 0.5-3 A/dm ${ }^{2}$ plating parameters. In the tin plating process, the samples were immersed in the alkaline caustic solution and degreased. Then, the electrolytic degreasing process was performed for $11 \mathrm{~A} / \mathrm{dm}^{2}$ and 3 minutes. After washing, the samples were etched with acid using $30 \% \mathrm{HCL}$ and $1 \%$ inhibitor. The samples that were washed after etching were tin-plated in $300 \mathrm{gr} / \mathrm{l}$ tin concentrate, at room temperature for $4.3-10.76 \mathrm{~A} / \mathrm{dm}^{2}$ and 20 minutes. 
Celal Bayar University Journal of Science

Volume 17, Issue 3, 2021, p 235-245

Doi:10.18466/cbayarfbe. 874287

Table 1. Codes, formulas and chemical compositions of the steels.

\begin{tabular}{cccccccccccc}
\hline \hline Code & DIN & $\mathrm{C}$ & $\mathrm{N}$ & $\mathrm{Si}$ & $\mathrm{P}$ & $\mathrm{S}$ & $\mathrm{Mn}$ & $\mathrm{Cr}$ & $\mathrm{Ni}$ & Mo & Rest \\
\hline 1.0037 & S235JR & 0.13 & 0.002 & - & 0.023 & 0.027 & 0.80 & - & - & - & $\mathrm{Fe}$ \\
1.6523 & 21NiCrMo2 & 0.19 & - & 0.04 & 0.015 & 0.025 & 0.74 & 0.56 & 0.65 & 0.23 & $\mathrm{Fe}$ \\
1.0503 & C45 & 0.43 & - & 0.40 & 0.020 & 0.027 & 0.73 & - & - & - & $\mathrm{Fe}$ \\
1.7225 & 42CrMo4 & 0.45 & - & 0.40 & 0.023 & 0.024 & 0.76 & 0.98 & - & 0.24 & $\mathrm{Fe}$ \\
\hline
\end{tabular}

Table 2. Some physical properties of the investigated materials. RM: Reference Materials)(\%).

\begin{tabular}{|c|c|c|c|c|c|c|c|}
\hline & Sample & $\begin{array}{l}\text { Mass } \\
(\mathrm{gr})\end{array}$ & $\begin{array}{l}\text { Thickness } \\
(\mathrm{cm})\end{array}$ & $\begin{array}{l}\text { Diameter } \\
(\mathrm{cm})\end{array}$ & $\begin{array}{l}\text { Radius } \\
(\mathrm{cm})\end{array}$ & $\begin{array}{l}\text { Volume } \\
\left(\mathrm{cm}^{3}\right)\end{array}$ & $\begin{array}{l}\text { Density } \\
\left(\mathrm{g} / \mathrm{cm}^{3}\right)\end{array}$ \\
\hline \multirow{4}{*}{$\mathbf{R M}$} & S235JR & 5.30 & 0.210 & 2.000 & 1.000 & 0.660 & 8.034 \\
\hline & 21NiCrMo2 & 4.90 & 0.215 & 1.970 & 0.985 & 0.655 & 7.477 \\
\hline & $\mathrm{C} 45$ & 4.08 & 0.180 & 2.010 & 1.005 & 0.571 & 7.143 \\
\hline & $42 \mathrm{CrMo} 4$ & 4.84 & 0.195 & 2.020 & 1.010 & 0.625 & 7.745 \\
\hline \multirow{4}{*}{ Ni Coated } & S235JR & 4.70 & 0.190 & 2.000 & 1.000 & 0.597 & 7.874 \\
\hline & 21NiCrMo2 & 4.60 & 0.210 & 1.950 & 0.975 & 0.627 & 7.335 \\
\hline & $\mathrm{C} 45$ & 5.04 & 0.205 & 2.000 & 1.000 & 0.644 & 7.826 \\
\hline & $42 \mathrm{CrMo} 4$ & 4.97 & 0.205 & 2.100 & 1.050 & 0.710 & 7.000 \\
\hline \multirow{4}{*}{ Ag Coated } & S235JR & 4.68 & 0.200 & 2.000 & 1.000 & 0.628 & 7.448 \\
\hline & 21NiCrMo2 & 4.36 & 0.195 & 1.955 & 0.978 & 0.585 & 7.448 \\
\hline & $\mathrm{C} 45$ & 4.78 & 0.200 & 2.000 & 1.000 & 0.628 & 7.608 \\
\hline & $42 \mathrm{CrMo} 4$ & 5.28 & 0.220 & 2.020 & 1.010 & 0.705 & 7.489 \\
\hline \multirow{4}{*}{ Cu Coated } & S235JR & 4.68 & 0.195 & 2.000 & 1.000 & 0.613 & 7.639 \\
\hline & $21 \mathrm{NiCrMo} 2$ & 4.63 & 0.200 & 1.950 & 0.975 & 0.597 & 7.752 \\
\hline & $\mathrm{C} 45$ & 5.30 & 0.215 & 2.000 & 1.000 & 0.675 & 7.847 \\
\hline & 42CrMo4 & 5.26 & 0.210 & 2.020 & 1.010 & 0.673 & 7.816 \\
\hline \multirow{4}{*}{ Sn Coated } & S235JR & 4.91 & 0.195 & 2.000 & 1.000 & 0.613 & 8.015 \\
\hline & 21NiCrMo2 & 4.59 & 0.200 & 1.956 & 0.978 & 0.601 & 7.638 \\
\hline & $\mathrm{C} 45$ & 5.22 & 0.220 & 2.000 & 1.000 & 0.691 & 7.553 \\
\hline & 42CrMo4 & 5.02 & 0.200 & 2.020 & 1.010 & 0.641 & 7.832 \\
\hline
\end{tabular}




\subsection{Radiation shielding process}

After the coating processes, S235JR, 21 NiCrMo2, C45, $42 \mathrm{CrMo} 4$ steels were irradiated by Ba-133 $(10 \mathrm{mCi})$ radioactive sources having $81-383 \mathrm{keV}$ energies to measure the LACs via the Beer-Lambert law (Figure. 2) and equation (Eq. 2.1);
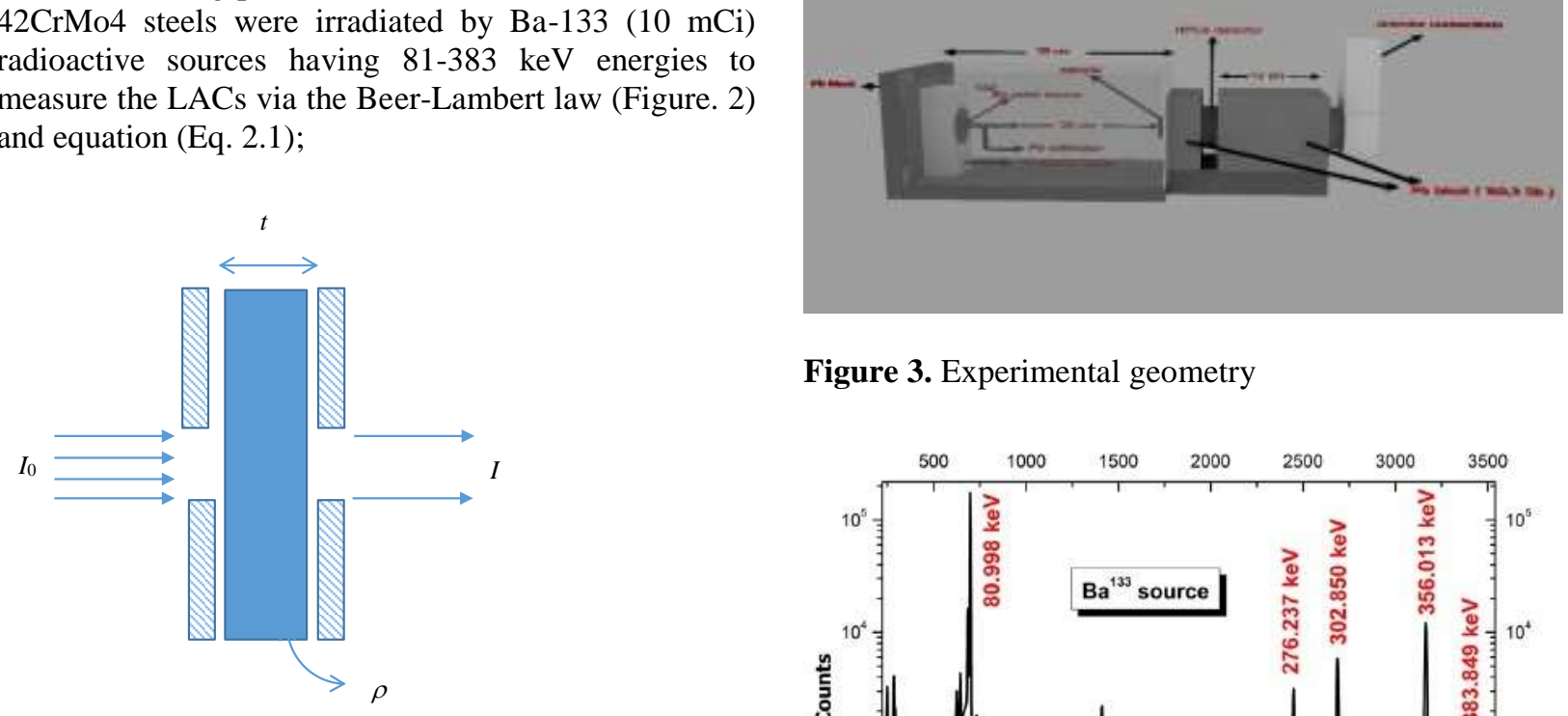

Figure 3. Experimental geometry

Figure 2. The experimental arrangement for transmission geometry

$I=I_{0} e^{-\mu x}, \mu=\frac{\ln \left(I_{0} / I\right)}{x}$

where $I_{0}$ and $I$ are unattenuated and attenuated photon intensities. MAC of any steel, which is a measure of the relative dominance of various interactions, was then determined via density $\left(\rho, \mathrm{g} \cdot \mathrm{cm}^{-3}\right)$ of the relevant material; $\mu_{m}=\mu / \rho\left(\mathrm{cm}^{2} \cdot \mathrm{g}-\right.$ $\left.{ }^{1}\right)$. A HPGe detector of $10 \mathrm{~mm}$ crystal length, $16 \mathrm{~mm}$ diameter and $200 \mathrm{~mm}^{2}$ active area was used to detect gamma rays. These HPGe detectors are known to have high detection efficiency at high energies. It has a resolution of $\sim 182 \mathrm{eV}$ at $5.9 \mathrm{keV}$ and its working voltage is $-1500 \mathrm{~V}$. A Tennelec 244 model amplifier was used and the measurement time for each sample was set to 1800s. Each sample has been measured at least three times and the results are given as the mean values along with standard deviation. Experimental geometry and a sample spectrum are given in Figures 3 and 4.

Half-value layer (HVL, cm) and tenth-value layer $(T V L, c m)$ are the thickness of the material at which the intensity of radiation entering it is reduced by one half and one tenth, and they were determined by;

$H V L=\frac{\ln (2)}{\mu}=\frac{0.693}{\mu}$ and $T V L=\frac{\ln (10)}{\mu}=\frac{2.302}{\mu}$

Mean free path (MFP, $\mathrm{cm}$ ), which is the average distance between two successive interactions, was calculated using the $\operatorname{LAC}\left(\mu, \mathrm{cm}^{-1}\right)$ of the steel from the equation;

$M F P=1 / \mu$

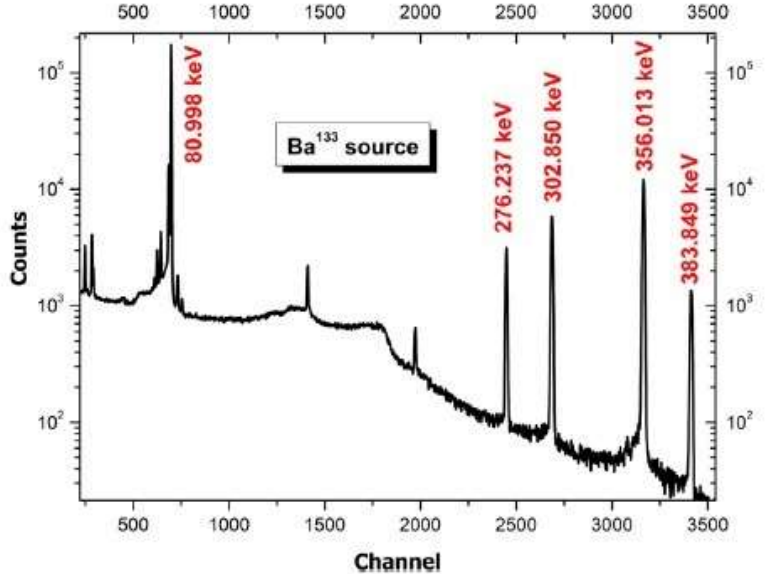

Figure 4. A sample spectrum for RM at studied energies

\section{Results and Discussion}

The reference materials (RM) 1.0037 (S235JR), 1.6523 (21NiCrMo2), 1.0503 (C45), 1.7225 (42CrMo4) steels were firstly coated with $\mathrm{Ni}, \mathrm{Cu}, \mathrm{Ag}$ and $\mathrm{Sn}$ heavy metals via mentioned processes. Mass (gr), thickness $(\mathrm{cm})$, diameter $(\mathrm{cm})$, radius $(\mathrm{cm})$, volume $\left(\mathrm{cm}^{3}\right)$ and density $\left(\mathrm{g} . \mathrm{cm}^{-3}\right)$ of coated materials were then determined using the Archimedes' principle using distilled water as an immersion liquid and a digital balance of sensitivity $10^{-4} \mathrm{~g}$. Measurements were repeated five times with an error of $<0.1 \%$. And the values are listed in Table 2 . After the physical measurements, LACs of the investigated reference and coated steels were measured with standard deviation as shown in Table 3. Pure (RM) S235JR, 21NiCrMo2, C45, 42CrMo4 steels and its coated (by heavy metals) forms were listed from Ni to Sn coated values to discuss the results in order. In addition, each steel and its coated forms were tabulated with increasing photon energy in the left column for evaluations. 
Table 3. LACs of the pure (RM) and different coated steels

\begin{tabular}{|c|c|c|c|c|c|c|c|c|c|c|}
\hline \multirow[b]{2}{*}{ Energy (keV) } & \multicolumn{5}{|c|}{ S235JR } & \multicolumn{5}{|c|}{ Std. Deviation } \\
\hline & $\mathbf{R M}$ & $\mathbf{N i}$ & $\mathbf{C u}$ & Ag & Sn & $\mathbf{R M}$ & $\mathrm{Ni}$ & $\mathbf{C u}$ & Ag & Sn \\
\hline 81 & 4.410 & 4.426 & 4.428 & 4.516 & 4.923 & 0.002 & 0.033 & 0.007 & 0.010 & 0.001 \\
\hline 160 & 1.383 & 1.551 & 1.542 & 1.638 & 1.697 & 0.049 & 0.025 & 0.011 & 0.008 & 0.016 \\
\hline 276 & 0.924 & 0.932 & 0.941 & 0.964 & 1.092 & 0.022 & 0.050 & 0.003 & 0.025 & 0.054 \\
\hline 302 & 0.836 & 0.841 & 0.845 & 0.852 & 0.959 & 0.002 & 0.012 & 0.018 & 0.006 & 0.038 \\
\hline 356 & 0.755 & 0.761 & 0.767 & 0.787 & 0.873 & 0.008 & 0.003 & 0.006 & 0.017 & 0.003 \\
\hline \multirow[t]{2}{*}{383} & 0.747 & 0.752 & 0.759 & 0.777 & 0.853 & 0.045 & 0.053 & 0.007 & 0.005 & 0.021 \\
\hline & \multicolumn{5}{|c|}{ 21NiCrMo2 } & \multicolumn{5}{|c|}{ Std. Deviation } \\
\hline Energy (keV) & $\mathbf{R M}$ & $\mathrm{Ni}$ & $\mathrm{Cu}$ & Ag & Sn & $\mathbf{R M}$ & $\mathbf{N i}$ & $\mathrm{Cu}$ & Ag & Sn \\
\hline 81 & 4.106 & 4.104 & 4.343 & 4.441 & 4.823 & 0.001 & 0.012 & 0.007 & 0.003 & 0.007 \\
\hline 160 & 1.271 & 1.517 & 1.560 & 1.586 & 1.719 & 0.061 & 0.008 & 0.099 & 0.004 & 0.034 \\
\hline 276 & 0.817 & 0.911 & 0.933 & 0.938 & 0.998 & 0.026 & 0.021 & 0.015 & 0.005 & 0.003 \\
\hline 302 & 0.782 & 0.801 & 0.830 & 0.846 & 0.853 & 0.001 & 0.029 & 0.009 & 0.001 & 0.014 \\
\hline 356 & 0.747 & 0.747 & 0.779 & 0.780 & 0.807 & 0.022 & 0.007 & 0.026 & 0.007 & 0.003 \\
\hline \multirow[t]{2}{*}{383} & 0.700 & 0.710 & 0.750 & 0.760 & 0.801 & 0.064 & 0.048 & 0.027 & 0.017 & 0.007 \\
\hline & \multicolumn{5}{|c|}{$\mathrm{C45}$} & \multicolumn{5}{|c|}{ Std. Deviation } \\
\hline Energy (keV) & $\mathbf{R M}$ & $\mathbf{N i}$ & $\mathrm{Cu}$ & Ag & Sn & $\mathbf{R M}$ & $\mathbf{N i}$ & $\mathrm{Cu}$ & Ag & Sn \\
\hline 81 & 3.820 & 4.231 & 4.258 & 4.419 & 4.440 & 0.005 & 0.011 & 0.010 & 0.015 & 0.003 \\
\hline 160 & 1.235 & 1.491 & 1.515 & 1.535 & 1.557 & 0.017 & 0.004 & 0.044 & 0.024 & 0.051 \\
\hline 276 & 0.815 & 0.903 & 0.907 & 0.920 & 0.945 & 0.003 & 0.015 & 0.022 & 0.006 & 0.029 \\
\hline 302 & 0.732 & 0.818 & 0.817 & 0.819 & 0.842 & 0.006 & 0.008 & 0.004 & 0.059 & 0.003 \\
\hline 356 & 0.679 & 0.748 & 0.744 & 0.755 & 0.768 & 0.001 & 0.004 & 0.010 & 0.010 & 0.002 \\
\hline \multirow[t]{2}{*}{383} & 0.669 & 0.738 & 0.736 & 0.745 & 0.758 & 0.027 & 0.069 & 0.105 & 0.023 & 0.015 \\
\hline & \multicolumn{5}{|c|}{ 42CrMo4 } & \multicolumn{5}{|c|}{ Std. Deviation } \\
\hline Energy (keV) & $\mathbf{R M}$ & $\mathbf{N i}$ & $\mathrm{Cu}$ & Ag & Sn & $\mathbf{R M}$ & $\mathbf{N i}$ & $\mathrm{Cu}$ & Ag & Sn \\
\hline 81 & 4.162 & 4.163 & 4.672 & 4.701 & 4.926 & 0.017 & 0.016 & 0.000 & 0.003 & 0.008 \\
\hline 160 & 1.306 & 1.321 & 1.485 & 1.583 & 1.670 & 0.012 & 0.017 & 0.022 & 0.032 & 0.021 \\
\hline 276 & 0.885 & 0.890 & 0.991 & 0.999 & 1.099 & 0.007 & 0.017 & 0.000 & 0.008 & 0.016 \\
\hline 302 & 0.847 & 0.841 & 0.929 & 0.931 & 0.952 & 0.009 & 0.011 & 0.026 & 0.018 & 0.036 \\
\hline 356 & 0.757 & 0.757 & 0.825 & 0.830 & 0.890 & 0.005 & 0.007 & 0.014 & 0.006 & 0.001 \\
\hline 383 & 0.725 & 0.722 & 0.753 & 0.813 & 0.859 & 0.006 & 0.097 & 0.026 & 0.053 & 0.012 \\
\hline
\end{tabular}

This method was also used for the other presentations of the parameters both figures and tables. When Table 3 is analyzed, energy dependences and coating effects on LAC values for the studied steels can be clearly seen found. So, LAC is decreasing with increasing photon energy as known, and values of LAC increase as atomic number of heavy coating metals at each photon energy from Table 3.

MAC values of the studied materials were then determined using densities of the materials from Table 2 as $\mu_{m}=\mu / \rho$. From this equation, it is clear that $\mu_{m}$ (MAC, mass attenuation coefficient) is proportional the $\mu$ (LAC, linear attenuation coefficient) for any material at the same photon energy. Thus, MAC values of the materials have the same energy dependences and the atomic number of coating heavy metal as seen from Figure 5 (a-d). MAC is a measure of the average number of interactions between incident photons and matter or is a measurement of how strongly a matter absorbs or scatters at a specific energy, per unit mass. And this parameter is a function of photon energy. It is also the fundamental property utilized in computations of the penetration of $\mathrm{X}$-and/or gamma rays for different types of materials such as shielding, health or the others. MAC values increase generally with increasing atomic number of coted metals from $\mathrm{Ni}$ to $\mathrm{Sn}$ in the worked photon energies $[21,22]$. In the light of this information, the more atomic number of coated heavy metals is higher, the more MAC is the higher at any specific photon energy from Figure 5 (a-d). It can consequently 
be said that coating process affects positively the MAC values of 1.0037 (S235JR), 1.6523 (21NiCrMo2), 1.0503 (C45), 1.7225 (42CrMo4) steels from the figure.

HVL and TVL are the significant thicknesses of the materials in terms of the radiation entering to matter. So, these parameters of the materials were obtained by using Eq. 2.2 at the investigated energies. Also, Table 4 shows HVLs and TVLs of the reference materials and the coated forms by heavy metals. HVL and TVL are inversely proportional to LAC. So, HVL and TVL values increase with increasing energy from 81 to 383 $\mathrm{keV}$ for any materials due to relations between these parameters and LACs. On the other hand, values of HVL and TVL reduce with rising atomic number of coated metals to the reference materials because of increasing LACs from $\mathrm{Ni}$ to $\mathrm{Sn}$ at each energy. And in this point, relations between HVL-TVL and LACs show its significance again on the radiation entering or shielding. As a result, coating process developed the HVL and TVL properties of the 1.0037 (S235JR), 1.6523 (21NiCrMo2), 1.0503 (C45), 1.7225 (42CrMo4) steels owing to diminishing HVL-TVL values from $\mathrm{Ni}$ to $\mathrm{Sn}$ coated metals at the studied energies.

MFP is one of the most significant parameters of materials on behalf of radiation attenuation or radiation shielding capability. The lower MFP values are desired for radiation shielding capability for any material thanks to its meaning. In other words, the less MFP is, the better radiation shielding capability is. Thus, MFP values of the materials were calculated by using Eq. 2.3 at the investigated photon energies. For this aim, values of LAC were utilized from Table 3, and the results were given in Figure 6 (a-d). MFP values are rising with increasing photon energy from 81 to $383 \mathrm{keV}$ for RMs (S235JR, 21NiCrMo2, C45, 42CrMo4) and its coted forms as shown in the figure. This is because of fact that MFP is function of LAC, and LAC are reducing with rising photon energy (from Table 3 ) for the materials. On the other hand, the studied materials were compared with some standard shielding concretes (Ordinary, Hematite-serpentine, Ilmenite-limonite, Basaltmagnetite, Ilmenite [23]) on behalf of MFP at possible energy $(356 \mathrm{keV})$ as seen in Figure 7 (a-d). It is clearly seen from the figure, both RMs (S235JR, 21NiCrMo2, $\mathrm{C} 45,42 \mathrm{CrMo} 4)$ and its coated forms (by heavy metals: from $\mathrm{Ni}$ to $\mathrm{Sn}$ ) have lower MFP values than standard shielding concretes at $356 \mathrm{keV}$. Therefore, one can say that investigated materials display the better radiation shielding capability than standard shielding concretes due to lower MFP values. Differences (\%) between RMs and coated forms on MFP values should be very important to describe improvements of materials. So, differences $(\%)$ were calculated by $\operatorname{diff} .(\%)=\frac{M F P_{R M}-M F P_{\text {coated }}}{M F P_{\text {coated }}} \times 100$ at the photon energies.

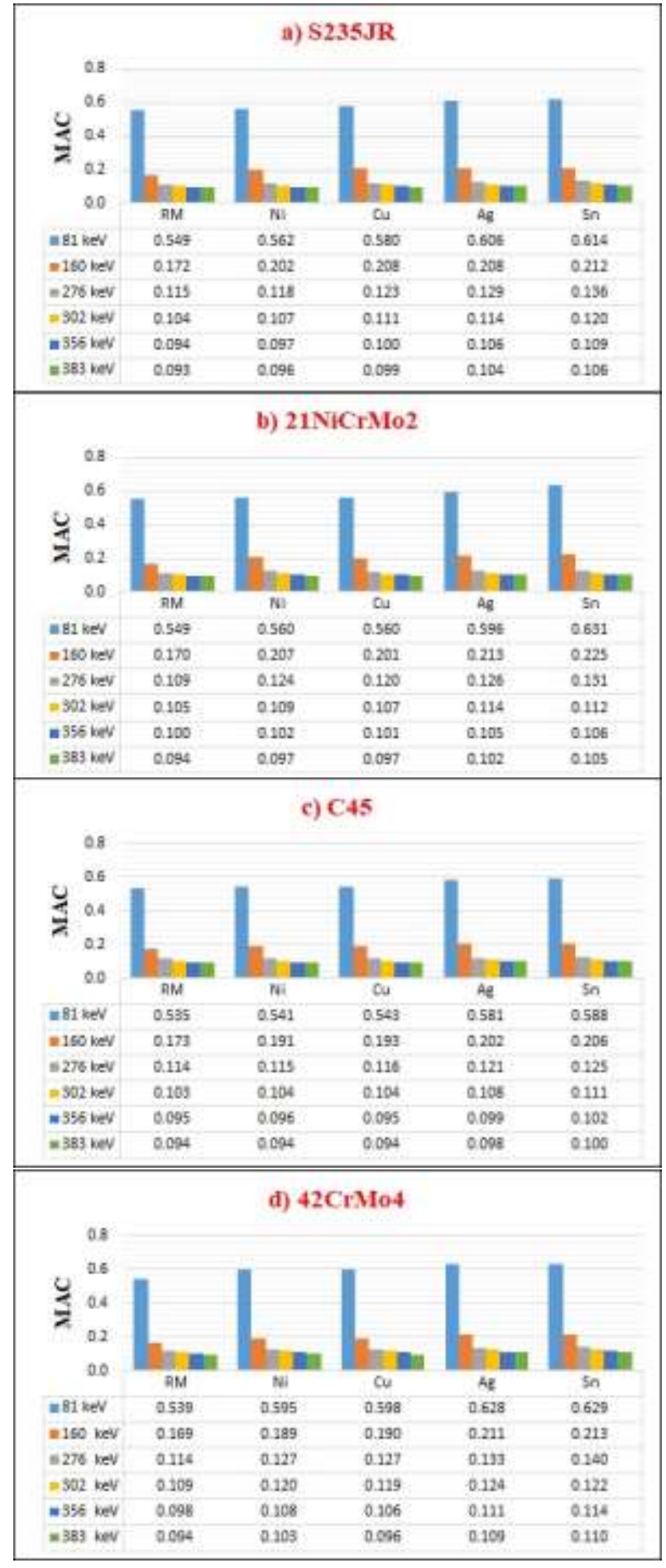

Figure 5. MACs $\left(\mathrm{cm}^{2} \cdot \mathrm{g}^{-1}\right)$ of coated steels at investigated energies. 
Table 4. HVLs and TVLs of the pure (RM) and different coated steels.

\begin{tabular}{|c|c|c|c|c|c|c|c|c|c|c|}
\hline \multirow[b]{3}{*}{ Energy (keV) } & \multicolumn{5}{|c|}{ HVL } & \multicolumn{5}{|c|}{ TVL } \\
\hline & \multicolumn{10}{|c|}{ S235JR } \\
\hline & RM & $\mathbf{N i}$ & $\mathrm{Cu}$ & $\mathrm{Ag}$ & Sn & RM & $\mathbf{N i}$ & $\mathrm{Cu}$ & $\mathbf{A g}$ & Sn \\
\hline 81 & 0.157 & 0.157 & 0.157 & 0.153 & 0.141 & 0.522 & 0.520 & 0.520 & 0.510 & 0.468 \\
\hline 160 & 0.501 & 0.450 & 0.447 & 0.423 & 0.409 & 1.664 & 1.493 & 1.485 & 1.406 & 1.357 \\
\hline 276 & 0.751 & 0.744 & 0.737 & 0.719 & 0.635 & 2.493 & 2.470 & 2.447 & 2.388 & 2.108 \\
\hline 302 & 0.829 & 0.824 & 0.821 & 0.814 & 0.723 & 2.753 & 2.736 & 2.726 & 2.703 & 2.402 \\
\hline 356 & 0.918 & 0.910 & 0.904 & 0.881 & 0.794 & 3.049 & 3.024 & 3.002 & 2.927 & 2.636 \\
\hline \multirow[t]{2}{*}{383} & 0.928 & 0.922 & 0.913 & 0.892 & 0.812 & 3.082 & 3.062 & 3.033 & 2.963 & 2.699 \\
\hline & \multicolumn{10}{|c|}{ 21 NiCrMo2 } \\
\hline Energy (keV) & $\mathbf{R M}$ & $\mathbf{N i}$ & $\mathrm{Cu}$ & Ag & Sn & $\mathbf{R M}$ & $\mathbf{N i}$ & $\mathrm{Cu}$ & Ag & Sn \\
\hline 81 & 0.169 & 0.169 & 0.160 & 0.156 & 0.144 & 0.561 & 0.561 & 0.530 & 0.519 & 0.477 \\
\hline 160 & 0.546 & 0.457 & 0.444 & 0.437 & 0.403 & 1.812 & 1.518 & 1.476 & 1.452 & 1.339 \\
\hline 276 & 0.848 & 0.761 & 0.743 & 0.739 & 0.695 & 2.818 & 2.527 & 2.469 & 2.455 & 2.308 \\
\hline 302 & 0.887 & 0.865 & 0.835 & 0.820 & 0.813 & 2.946 & 2.875 & 2.774 & 2.723 & 2.701 \\
\hline 356 & 0.928 & 0.928 & 0.889 & 0.888 & 0.859 & 3.084 & 3.082 & 2.955 & 2.951 & 2.853 \\
\hline \multirow[t]{2}{*}{383} & 0.991 & 0.977 & 0.925 & 0.913 & 0.866 & 3.291 & 3.245 & 3.072 & 3.031 & 2.876 \\
\hline & \multicolumn{10}{|c|}{$\mathrm{C} 45$} \\
\hline Energy (keV) & $\mathbf{R M}$ & $\mathbf{N i}$ & $\mathrm{Cu}$ & $\mathbf{A g}$ & Sn & $\mathbf{R M}$ & $\mathbf{N i}$ & $\mathrm{Cu}$ & $\mathbf{A g}$ & Sn \\
\hline 81 & 0.181 & 0.164 & 0.163 & 0.157 & 0.156 & 0.603 & 0.544 & 0.541 & 0.521 & 0.519 \\
\hline 160 & 0.561 & 0.465 & 0.458 & 0.452 & 0.445 & 1.864 & 1.544 & 1.520 & 1.500 & 1.479 \\
\hline 276 & 0.850 & 0.767 & 0.764 & 0.753 & 0.733 & 2.824 & 2.549 & 2.538 & 2.502 & 2.436 \\
\hline 302 & 0.946 & 0.848 & 0.848 & 0.847 & 0.823 & 3.144 & 2.816 & 2.818 & 2.813 & 2.734 \\
\hline 356 & 1.021 & 0.927 & 0.931 & 0.919 & 0.903 & 3.393 & 3.080 & 3.093 & 3.051 & 3.000 \\
\hline \multirow[t]{2}{*}{383} & 1.036 & 0.940 & 0.941 & 0.931 & 0.915 & 3.441 & 3.122 & 3.127 & 3.092 & 3.040 \\
\hline & \multicolumn{10}{|c|}{$42 \mathrm{CrMo} 4$} \\
\hline Energy (keV) & $\mathbf{R M}$ & $\mathbf{N i}$ & $\mathrm{Cu}$ & Ag & Sn & $\mathbf{R M}$ & $\mathbf{N i}$ & $\mathrm{Cu}$ & $\mathbf{A g}$ & Sn \\
\hline 81 & 0.167 & 0.167 & 0.148 & 0.147 & 0.141 & 0.553 & 0.553 & 0.493 & 0.490 & 0.467 \\
\hline 160 & 0.531 & 0.525 & 0.467 & 0.438 & 0.415 & 1.763 & 1.743 & 1.550 & 1.455 & 1.379 \\
\hline 276 & 0.783 & 0.779 & 0.699 & 0.694 & 0.631 & 2.603 & 2.586 & 2.323 & 2.305 & 2.095 \\
\hline 302 & 0.819 & 0.824 & 0.746 & 0.745 & 0.728 & 2.720 & 2.737 & 2.480 & 2.475 & 2.418 \\
\hline 356 & 0.915 & 0.916 & 0.840 & 0.835 & 0.779 & 3.041 & 3.042 & 2.791 & 2.775 & 2.587 \\
\hline 383 & 0.956 & 0.960 & 0.920 & 0.853 & 0.807 & 3.177 & 3.190 & 3.056 & 2.833 & 2.680 \\
\hline
\end{tabular}




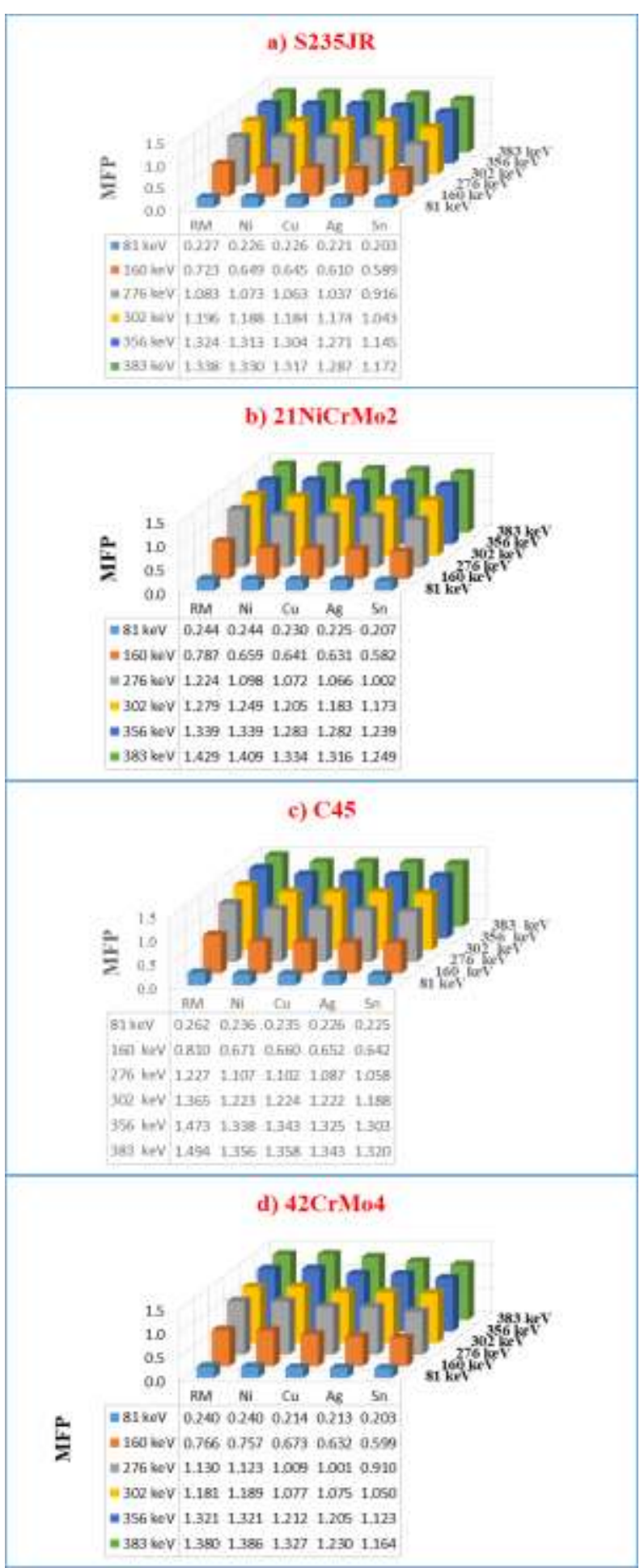

Figure 6. MFPs $(\mathrm{cm})$ of coated steels at investigated energies

Relative differences were generally increased from $\mathrm{Ni}$ to $\mathrm{Sn}$ coating forms of the materials, and maximum relative difference was determined to be $35.31 \%$ for $\mathrm{Sn}$ coated $1.6523(21 \mathrm{NiCrMo} 2)$ steel. This shows that coating process used has positively affected the RM materials on account of MFP which is very significant feature of radiation shielding applications.

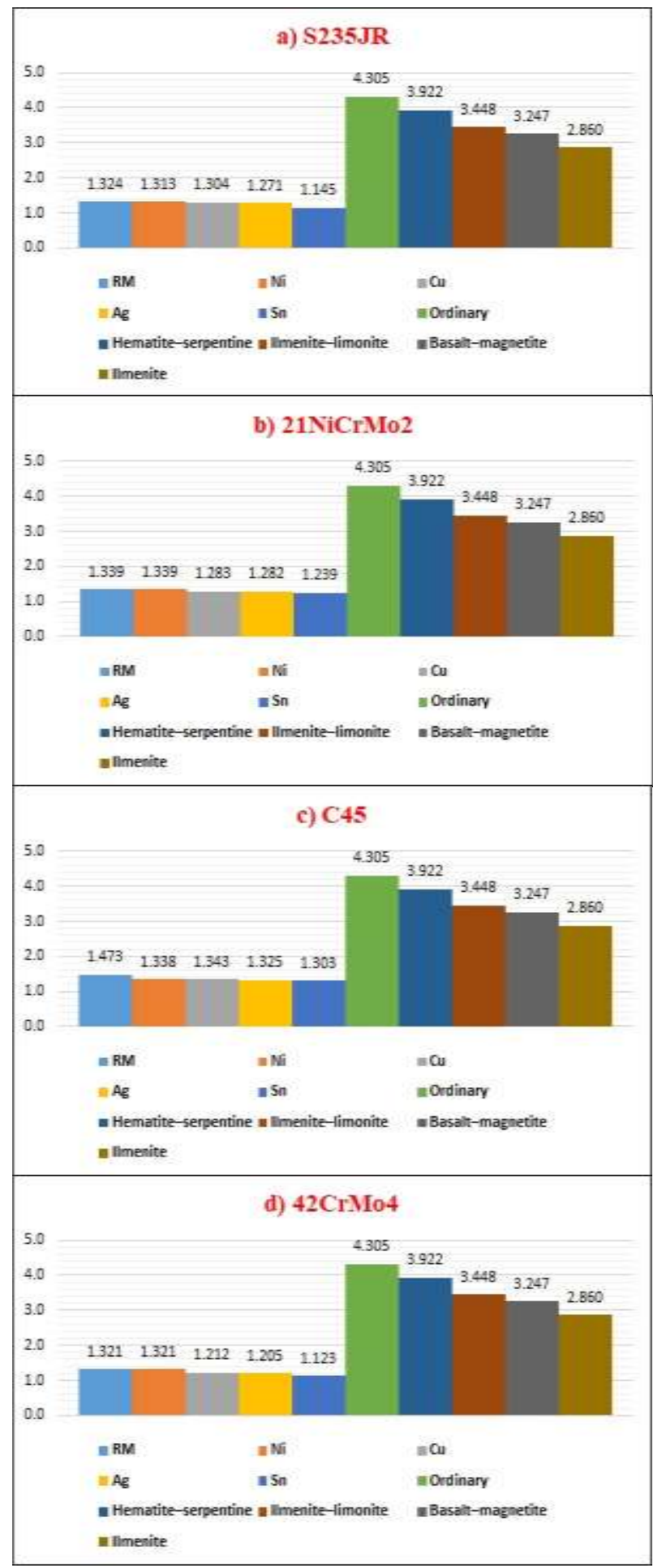

Figure 7. MFPs (cm) of coated steels and some standard shielding concretes at $356 \mathrm{keV}$ photon energy

\section{Conclusion}

It was aimed to improve 1.0037 (S235JR), 1.6523 (21NiCrMo2), 1.0503 (C45), 1.7225 (42CrMo4) steels using coating process the materials in terms of the radiation shielding capability as much as possible in the present study. 1.0037 (S235JR), 1.6523 (21NiCrMo2), 
1.0503 (C45), 1.7225 (42CrMo4) pure steels were coated by $\mathrm{Ni}, \mathrm{Cu}, \mathrm{Ag}$ and $\mathrm{Sn}$ heavy metals via electrolytic plating method to measure radiation attenuation properties. The pure and coated samples were then irradiated by radioactive sources for transmission of the gamma rays at $81-383 \mathrm{keV}$ photon energies to measure linear and mass attenuation coefficients (LAC- $\mu$, MAC- $\mu / \rho)$. Mean free path (MFP), Half and tenth value of layers (HVL and TVL) of investigated materials were then calculated at the same studied photon energies. The coated steels were found to be better shielding materials than the concretes due to higher LACs and MACs, and lower MFP values. Coated steels were also better shielding than reference materials up to $35.31 \%$ relative difference in MFP. One can obviously say that coating processes improve the radiation shielding capability of the studied steels, and the materials have excellent shielding features against the rays according to standard concretes.

\section{Author's Contributions}

İdris Karagöz: Sample preparation, characterization progresses, methodology.

Erdem Şakar: Made the experiments, data curation, software.

Murat Türemiş: Data curation, investigation, helped in manuscript preparation.

Mehmet Büyükyıldız: Made literature search, writing review \& editing.

\section{Ethics}

There are no ethical issues after the publication of this manuscript.

\section{References}

1. Raj, B, Mudali, UK, Vijayalakshmi M, Mathew MD, Bhaduri, AK, Chellapandi, P, Venugopal, S, Sundar, CS, Rao, BPC, Venkataraman, B. 2013. Development of stainlesss steels in nuclear industry: with emphasis on sodium cooled fast spectrum reactors: history, technology and foresight. Advanced Materials Research; 794: 3-25. https://doi.org/10.4028/www.scientific.net/AMR.794.3

2. Cattant, F, Crusset, D, Féron, D. 2008. Corrosion issues in nuclear industry today. Materials Today; 11(10): 32-37. https://doi.org/10.1016/S1369-7021(08)70205-0

3. El-Kateb, AH, Rizk, RAM., Abduk-Kader, AM. 2000 Determination of atomic cross-sections and effective atomic numbers for some allays. Annals of Nuclear Energy; 27(14), 1333-1343. https://doi.org/10.1016/S0306-4549(99)00121-8

4. Akkurt, I. 2009. Effective atomic and electron numbers of some steels at different energies. Annals of Nuclear Energy; 36(11-12): 1702-1705. https://doi.org/10.1016/j.anucene.2009.09.005

5. Medhat, ME, Wang, Y. 2015. Investigation on radiation shielding parameters of oxide dispersion strengthened steels used in high temperature nuclear reactor applications. Annals of Nuclear Energy; 80: 365-370.https://doi.org/10.1016/j.anucene.2015.01.044

6. Singh, VP, Medhat, ME, Shirmardi, SP. 2015. Comparative studies on shielding properties of some steel alloys using Geant4, MCNP,
WinXCOM and experimental results. Radiation Physics and Chemistry; 106: 255-260. https://doi.org/10.1016/j.radphyschem.2014.07.002

7. Yıldırım, S, Tugrul, AB, Buyuk, B, Demir, E. 2016. Gamma Attenuation properties of some aluminum alloys. Acta Physica

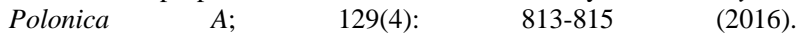
https://doi.org/10.12693/APhysPolA.129.813

8. Büyükyıldız, M, Kurudirek, M, Ekici, M, İçelli, O, Karabul, Y. 2017. Determination of radiation shielding parameters of $304 \mathrm{~L}$ stainless steel specimens from welding area for photons of various gamma ray sources. Progress in Nuclear Energy; 100: 244-254. https://doi.org/10.1016/j.pnucene.2017.06.014

9. Büyükyıldız, M.. 2018. Effect of current intensity on radiological properties of joined 304L stainless steels for photon interaction. Nuclear Science Techniques; 29:8,. https://doi.org/10.1007/s41365017-0353-1

10. Akman,, F, Sayyed, MI, Kaçal MR, Tekin, HO. 2019. Investigation of photon shielding performances of some selected alloys by experimental data, theoretical and MCNPX code in the energy range of $81 \mathrm{keV}-1333 \mathrm{keV}$. Journal of Alloys and Compounds; 772: 516-524. https://doi.org/10.1016/j.jallcom.2018.09.177

11. Yılmaz, D, Aktaș, B, Çalık, A, Aytar, OB. 2019.Boronizing effect on the radiation shielding properties of Hardox 450 and Hardox HiTuf steels. Radiation Physics and Chemistry; 161: 55-59. https://doi.org/10.1016/j.radphyschem.2019.04.019

12. Li, J, Huang, M, Hou, R, Ouyang, X. 2019. Photon attenuation coefficients of oxide dispersion strengthened steels by Geant4, XCOM and experimental data. Radiation Physics and Chemistry; 161: 23-28. https://doi.org/10.1016/j.radphyschem.2019.03.042

13. Şakar, E, Büyükyıldız, M, Alım, B, Şakar, BC, Kurudirek, M. 2019. Leaded brass alloys for gamma-ray shielding applications. $\begin{array}{llll}\text { Radiation Physics and Chemistry; 159, 64-69. } & \end{array}$ https://doi.org/10.1016/j.radphyschem.2019.02.042

14. Akman, F, Kaçal, MR, Sayyed MI, Karataş HA. 2019. Study of gamma radiation attenuation properties of some selected ternary alloys. Journal of Alloys and Compounds; 782: 315-322. https://doi.org/10.1016/j.jallcom.2018.12.221

15. Alım, B, Şakar, E, Baltakesmez, A, Han, İ, Sayyed, MI, Demir, L. 2020. Experimental investigation of radiation shielding performances of some important AISI-coded stainless steels: Part I. Radiation Physics and Chemistry; 166: 108455. https://doi.org/10.1016/j.radphyschem.2019.108455

16. Alım, B, Şakar, E, Han, İ, Sayyed, MI. 2020. Evaluation the gamma, charged particle and fast neutron shielding performances of some important AISI-coded stainless steels: Part II. Radiation Physics $\begin{array}{lll}\text { and Chemistry; } & 166, & 108454 .\end{array}$ https://doi.org/10.1016/j.radphyschem.2019.108455

17. Sterne, JrRH, Steele, LE. 1969. Steels for commercial nuclear power reactor pressure vessels. Nuclear Engineering and Design; 10(3): 259-307,. https://doi.org/10.1016/0029-5493(69)90066-1

18. Neff, D, Saheb, M, Monnier, J, Perrin, S, Descostes, M, L'Hostis, V, Crusset, D, Millard, A, Dillmann, P. 2010. A review of the archaeological analogue approaches to predict the long-term corrosion behaviour of carbon steel overpack and reinforced concrete structures in the French disposal systems. Jornal of Nuclear Materials; 402: 196-205. https://doi.org/10.1016/j.jnucmat.2010.05.003

19. Finniston, HM. 1974. The sixth royal society technology lecture: Nuclear energy for the steel industry. Proceedings of the Royal Society A; 340: 139-146. http://www.jstor.org/stable/78625 
[20]. Standish, T, Chen, J, Jacklin, R, Jakupi, P, Ramamurty, S, Zagidulin, D, Keech, P, Shoesmith, D. 2016. Corrosion of coppercoated steel high level nuclear waste containers under permanent disposal conditions. Electrochimica Acta; 211: 331-342. https://doi.org/10.1016/j.electacta.2016.05.135

[21]. Seltzer, SM, Hubbell, JH. Tables and Graphs of Photon Mass Attenuation Coefficient and Mass Energy-Absorption Coefficients for Photon Energies $1 \mathrm{keV}$ to $20 \mathrm{MeV}$ for Elements $Z=1$ to 92 and Some Dosimetric Materials, Appendix to invited plenary lecture by J.H. Hubbell "45 Years (1950-1995) with X-Ray Interactions and Applications" presented at the 51st National Meeting of the Japanese Society of Radiological Technology, April 14-16, Nagoya, Japan, 1995.

[22]. Gerward, L, Guilbert, N, Jensen, KB, Levring, H. 2004. WinXCom-a program for calculating X-ray attenuation coefficients. Radiation Physics and Chemistry; 71:(3-4): 653-654. https://doi.org/10.1016/j.radphyschem.2004.04.040

[23]. Bashter, II. 1997. Calculation of radiation attenuation coefficients for shielding concretes. Annals of Nuclear Energy; 24(17): 1389-1401. https://doi.org/10.1016/S0306-4549(97)00003-0 